\title{
FATORES DETERMINANTES DA POLÍTICA DE EXECUÇÃO ORÇAMENTÁRIA NO BRASIL (1980-2018)
}

\author{
Maurício Corrêa da Silva ${ }^{1}$ \\ João Carlos Hipólito Bernardes do Nascimento 2 \\ José Dionísio Gomes da Silva ${ }^{3}$
}

- Artigo recebido em: 24/07/2019 -- Artigo aceito em: 18/06/2020 -.' Segunda versão aceita em: 04/02/2021

\section{RESUMO}

Os estudos orçamentários no Brasil são eminentemente técnicos, sendo que poucos se utilizam de modelos teóricos para examinar e compreender o comportamento das decisões no processo orçamentário. Este artigo tem o objetivo de analisar, dentre um conjunto de fatores, quais foram os determinantes da política de execução orçamentária no Brasil, no período de 1980 a 2018. A investigação utiliza a Teoria Incremental e a Teoria do Equilíbrio Pontuado como suporte para elaborar a variável dependente (variações incrementais e/ou pontuais nas decisões de implementação do Orçamento Federal) e assim testar hipóteses de fatores determinantes com base em estudos empíricos (variáveis explicativas). Os resultados demonstraram que as variáveis receita arrecadada e - Produto Interno Bruto per capita apresentaram efeito positivo e significativo com a execução da despesa orçamentária (variações de estabilidade e pontuadas), ou seja, maiores arrecadações e Produto Interno Bruto per capita acarretam no incremento dos serviços públicos a nível federal. Contudo, como os recursos são escassos, deve-se observar que os níveis de gastos devem ter

\footnotetext{
1 Doutor em Ciências Contábeis (UnB/UFPB/UFRN). Professor Adjunto do Departamento de Ciências Contábeis da Universidade Federal do Rio Grande do Norte (UFRN). Professor do Mestrado em Ciências Contábeis da UFRN. Endereço: Av. Senador Salgado Filho, S/N Campus Universitário - Lagoa Nova Natal - RN - Brasil - CEP 59076-000 - Universidade Federal do Rio Grande do Norte (UFRN) - Centro de Ciências Sociais Aplicadas (CCSA) Departamento de Ciências Contábeis (DCC). Telefone: (81) 3215.3486. E-mail: prof.mauriciocsilva@gmail.com.

http://orcid.org/0000-0003-2036-5237

2 Doutor em Ciências Contábeis (UFRJ). Professor Adjunto da Universidade Federal do Piauí (UFPI). Professor do Mestrado de Gestão Pública da UFPI. Endereço: Universidade Federal do Piauí (UFPI) - BR - 343, KM 3,5 - Meladão - Cidade de Floriano - PI, Brasil - CEP 64.808-605. Telefone: (089) 35221768. E-mail: jchbn1@gmail.com.

https://orcid.org/0000-0003-3505-372X
}

${ }^{3}$ Doutor em Controladoria e Contabilidade (FEA-USP). Professor Adjunto do Departamento de Ciências Contábeis da UFRN e do Mestrado em Ciências Contábeis da UFRN. Endereço: Av. Senador Salgado Filho, S/N - Campus Universitário - Lagoa Nova Natal - RN - Brasil - CEP 59076000 - Universidade Federal do Rio Grande do Norte (UFRN) - Centro de Ciências Sociais Aplicadas (CCSA) - Departamento de Ciências Contábeis (DCC). Telefone: (81) 3215.3486. Email: dionisio@ufrnet.br.

https://orcid.org/0000-0002-7289-0220

Editor responsável pela aprovação do artigo: Dr. Eduardo Mendes Nascimento Editora responsável pela edição do artigo: $\mathrm{Dr}^{\mathrm{a}}$. Bruna Camargos Avelino 
correlação com o crescimento econômico. A variável número de habitantes (população) tem efeito negativo e significativo com a execução orçamentária da despesa, sinalizando que o aumento do número de habitantes provoca uma diminuição no atendimento por parte do Estado em serviços públicos, principalmente com o envelhecimento da população. As variáveis da oposição partidária dos Presidentes da Câmara dos Deputados e do Senado Federal ao Presidente da República (competição política) não apresentaram significância estatística.

Palavras-chave: Política pública orçamentária. Fatores determinantes. Brasil. Teoria incremental. Teoria do equilíbrio pontuado.

\title{
DETERMINING FACTORS OF THE BUDGET EXECUTION POLICY IN BRAZIL (1980-2018)
}

\begin{abstract}
Budget studies in Brazil are eminently technical, with only a few utilizing theoretical models to examine and understand the behavior of the decisions in the budget process. This purpose of this study is to analyze, among a set of factors, which ones were the determining for the budget execution policy in Brazil, in the period from 1980 to 2018. The study uses the Incremental Theory and the Punctuated Equilibrium Theory as support to develop the dependent variable (incremental and/or one-off variations in the decisions of implementation of the Federal Budget) and, thus, to test hypotheses of determining factors based on empirical studies (explanatory variables). The results showed that the variables "collected revenue" and per capital Gross Domestic Product showed a positive and significant effect with the execution of the budget expenditure (stability and punctuated variations), that is, larger revenues and per capita Gross Domestic Product result in an increment of public services at federal level. However, as resources are scarce, one must observe that the spending levels must be correlated with the economic growth. The variable "number of inhabitants (population)" has a negative and significant effect with the budget execution of the expenditure, signaling that the increase in the number of inhabitants causes a reduction in the provision of public services by the State/Public Administration, especially in view of the population's aging process. The variables related to the "political opposition" from the Presidents of the Lower House and from the Federal Senate to the President of the Republic (political competition) did not show statistical significance.
\end{abstract}

Keywords: Budget public policy. Determining factors. Brazil. Incremental theory. Punctuated equilibrium theory.

\section{INTRODUÇÃO}

No processo de formulação de políticas públicas, os problemas são conceituados e levados ao governo para solução; as instituições governamentais formulam alternativas e selecionam as soluções políticas que são, em seguida, implementadas, avaliadas e revisadas. Nessa linha, as políticas orçamentárias podem ser analisadas por vários frameworks teóricos: estágios heurísticos; escolha 
racional institucional; múltiplos fluxos; estrutura de equilíbrio pontuado; quadro de coalizão de advocacia; estrutura de difusão de políticas, incremental e o funil de causalidade (Sabatier, 2007).

A Teoria do Equilíbrio Pontuado, para True, Jones e Baumgartner (2007), explica a estabilidade e a mudança na formulação de políticas públicas. $O$ incrementalismo e as teorias racionais de maximização de preferência não conseguem analisar os períodos de atenção limitados nos governos e nas pessoas. Na Teoria Incremental, segundo Davis, Dempster e Wildavsky (1966), a base orçamentária é o valor autorizado pelo Congresso no ano anterior e sua utilização defende o status quo contra as demandas por mudanças da relação política e orçamentária.

O incrementalismo pressupõe que a solicitação da dotação orçamentária de um ano é composta por uma parcela fixa e outra variável e estocástica, considerada incremental. A parcela fixa é considerada a base orçamentária, significando o resultado de um consenso político no qual estabelece o grau de participação de cada ação no agregado geral (Abreu, Neiva \& Lima, 2012).

O processo orçamentário para as três esferas de governo no Brasil, segundo Alves (2016), sofre forte influência incremental. Os estudos orçamentários no Brasil são eminentemente técnicos, sendo que poucos utilizam-se de modelos teóricos para examinar e compreender o comportamento das decisões no processo orçamentário, cenário que não ocorre no contexto internacional (por exemplo, Bezdek, Dybczak \& Krejdl, 2003; Ferris, Park \& Winer, 2008; Hobolt \& Klemmensen. 2008; Rosenthal \& Wolfson, 2013; Ukwueze, 2015; Lojanica, 2015; Zokalj, 2016; Thomson et al., 2017; Demera \& Yemer, 2018).

Nesta perspectiva, Rosenthal e Wolfson (2013) examinaram os determinantes da implementação orçamentária em Israel. Como variável dependente, utilizaram o uso dos orçamentos pelo governo (soma dos orçamentos implementados por um ministério) e como variáveis independentes testaram três grupos conceituais: o ambiente político do ministério (posições de política partidária do ministro, o tempo do ministro, o poder de barganha do partido do ministro, a fragmentação e a estabilidade da coalizão); a função burocrática do ministério e os efeitos do processo de execução orçamental (choques macroeconômicos: Produto Interno Bruto per capita, taxa de desemprego, o Índice Gini como fator de desigualdade socioeconômica e a taxa de inflação).

Os principais resultados da pesquisa de Rosenthal e Wolfson (2013) evidenciaram que ter uma negociação mais alta em torno da mesa do governo não é suficiente para aumentar a execução orçamentária; o orçamento do ano passado é um forte indicador do orçamento do ano em curso, existindo um efeito positivo no uso da interação entre as posições políticas e a eficácia partidária. Por fim, notou-se que ter um poder de ameaça credível sobre a burocracia aumenta a implementação orçamentária.

Demera e Yemer (2018) investigaram os determinantes do controle orçamentário em organizações públicas no Estado Regional de Benishangul Gumuz, na Etiópia. Como variável dependente, utilizaram o grau de controle do orçamento e como variáveis independentes: o processo de planejamento orçamentário; o suporte gerencial; a equipe de auditoria interna; o comprometimento organizacional; o monitoramento e avaliação orçamentária; 
a informação e a comunicação e a redução de custos. Os resultados demonstram, que, com exceção do processo de planejamento orçamentário realizado pelos escritórios do setor público, as demais variáveis independentes contribuíram para o controle orçamentário do setor público de forma significativa e positiva.

Diante do exposto, surge a seguinte pergunta de pesquisa: Quais foram os fatores determinantes da política de execução orçamentária no Brasil, no período de 1980 a 2018 ? Dessa forma, o objetivo geral deste estudo é analisar, dentre um conjunto de fatores, quais foram os determinantes da política de execução orçamentária no Brasil, no período de 1980 a 2018. Como objetivos específicos desta investigação, destacam: elencar fatores que podem determinar a política de execução orçamentária; identificar as variações percentuais das despesas orçamentárias; estimar um modelo regressivo empírico para testar os fatores explicativos.

A pesquisa potencialmente ampliará a discussão sobre os estudos orçamentários no Brasil, além de contribuir para a literatura sobre fatores que podem ser considerados determinantes nas decisões orçamentárias. Os resultados da pesquisa poderão sinalizar, de forma prospectiva, para os decisores políticos, fatores que deverão ser discutidos na política orçamentária. Outra consequência do estudo ocorre no possível estímulo para a realização de mais pesquisas empíricas correlatas para fomentar as discussões para um tema tão relevante para a sociedade detentora dos recursos públicos: a forma como os gestores públicos utilizam esses recursos.

Dada a complexidade do processo de políticas públicas, este estudo utiliza a Teoria Incremental e a Teoria do Equilíbrio Pontuado como suporte para elaborar a variável dependente (variações incrementais e/ou pontuais nas decisões de implementação do Orçamento Federal, no período de 1980 a 2018) e assim testar hipóteses de fatores determinantes com base em estudos empíricos (variáveis explicativas). Desse modo, para cumprir com o objetivo proposto, a investigação está dividida em cinco tópicos. Após essa introdução, o tópico seguinte trata do referencial teórico (teorias sobre políticas públicas orçamentárias; estudos empíricos sobre as Teorias do Equilíbrio Pontuado e Incremental e hipóteses do estudo), seguido dos procedimentos metodológicos, dos resultados e discussões. A investigação é finalizada com o tópico das considerações finais e das referências utilizadas.

\section{REVISÃO DA LITERATURA}

\subsection{Teorias sobre Políticas Públicas Orçamentárias}

Os modelos teóricos mais utilizados nos estudos orçamentários são quatro: incremental, de julgamento serial, de fluxos múltiplos e de equilíbrio pontuado. 0 incremental, mais conhecido no Brasil, parte do pressuposto que cada orçamento é elaborado com base no anterior. $O$ modelo de julgamento serial explica o comportamento orçamentário como resultado de ações que seguem passos sequenciais para estabelecer objetivos e resolver problemas, explorando estratégias alternativas para alcançar esses objetivos. O modelo de fluxos múltiplos analisa como as políticas entram no orçamento governamental, focalizando três fluxos (problemas, soluções propostas e o político). O modelo do 
equilíbrio pontuado analisa por que processos políticos, ocasionalmente, produzem grandes variações (Ollaik et al., 2011).

A teoria empírica do modelo incremental foi desenvolvida a partir dos estudos de Davis, Dempster e Wildavsky, apresentada no artigo A Theory of the Budgetary Process no ano de 1966. Os autores apresentaram uma análise resumida do processo orçamentário federal nos Estados Unidos da América, explicando, através de um modelo relativamente simples, linear e estocástico, o porquê de a característica básica desse processo ser a estabilidade ao longo do tempo (Fernandes \& Alves, 2017).

Para Davis, Dempster e Wildavsky (1966), o processo orçamentário norteamericano pode ser representado por equações lineares, sendo que um conjunto simples de regras é responsável pela tomada de decisão no processo orçamentário. Existe uma forte interdependência entre os agentes (o que o Poder Executivo faz depende do que o Congresso fez e vice-versa) e esboços empíricos sobre orçamento público são fundamentais para a compreensão desse processo.

Abreu, Neiva e Lima (2012) esclarecem que a análise incremental, ou incrementalismo, sugerida por Lindblom, é uma abordagem ampla relacionada à teoria da decisão. Sua lógica foi estendida ao contexto orçamentário a partir das suposições de Wildavsky, de que se o processo orçamentário é baseado em políticas incrementais, então o orçamento também é incremental. A existência da base orçamentária implica em processos orçamentários sequenciais e repetitivos, o que sugere a estabilidade no processo.

De acordo com Padgett (1980), as teorias de racionalidade limitadas da tomada de decisão (Teoria do Julgamento Serial e Teoria do Incrementalismo) sobre o orçamento federal dos Estados Unidos foram analisadas empiricamente com dados do orçamento por Eisenhower, Kennedy e Johnson e a conclusão principal foi que a Teoria do Julgamento Serial supera a Teoria do Incrementalismo proposta por Davis, Dempster e Wildavsky. A Teoria do Julgamento Serial prevê não apenas que a maior parte dos programas receberá, na maioria das vezes, alocações apenas marginalmente diferentes da base histórica, mas também que mudanças ocasionais, radicais e até "catastróficas", são o resultado normal da tomada de decisões orçamentárias federais rotineiras.

O processo de formulação de políticas públicas é normalmente complexo, envolvendo diversos atores e grupos de interesse, como instituições governamentais, partidos políticos, sociedade organizada, entre outros. Muitas vezes, esses atores agem de forma antagônica, fazendo com que o processo de escolhas eficientes se torne fundamental. O modelo de julgamento serial desenvolvido por Padgett se insere no paradigma da racionalidade limitada, diferenciando-se do incrementalismo por força da análise sequencial de dados e pela falta de determinismo no resultado final da análise. Nesse modelo, o tomador de decisão inicia com uma base fixa, toma sua decisão sobre a direção que irá assumir (aumentos ou reduções na alocação orçamentária, diante de uma escolha binária que baliza as subsequentes alternativas relevantes para o tomador de decisões), busca alternativas discretas no orçamento, para em seguida aplicar a teoria do julgamento serial (Abreu, Neiva \& Lima, 2012).

A estrutura de múltiplos fluxos foi desenvolvida por John Kingdon em 1984 com base no modelo de comportamento organizacional da "lata de lixo". Ele considera o processo político como composto por três fluxos de atores e 
processos: (i) um fluxo de problemas que consiste em dados sobre vários problemas e os proponentes de várias definições de problemas; (ii) um fluxo de políticas envolvendo os proponentes de soluções para os problemas de políticas; (iii) um fluxo político composto por eleições e autoridades eleitas. Na visão de Kingdon, os fluxos normalmente operam independentemente um do outro, exceto quando da ocorrência de uma "janela de oportunidade", que permite aos empreendedores de políticas unirem os vários fluxos. Se os empreendedores forem bem-sucedidos, o resultado é uma grande mudança de política (Sabatier, 2007).

A Teoria do Equilíbrio Pontuado foi formulada na biologia evolutiva em 1954, quando Ernst Mayr teorizou que a evolução biológica não ocorre gradualmente e sim por mutação, recombinação e seleção natural em populações. Em 1972, os paleontologistas Stephen J. Gould e Niles Eldredge argumentaram, em seu ensaio Models of Paleobiology, que a mudança evolucionária biológica nem sempre foi "lenta e constante" ou gradual como foi mantida por Charles Darwin em 1859 (Givel, 2010).

As pesquisas da Teoria do Equilíbrio Pontuado em políticas públicas ocorreram em 1993 e em 2009, quando os cientistas políticos Frank Baumgartner e Bryan Jones, tomando emprestados os primeiros resultados científicos de equilíbrio pontuado de Gould e Eldredge, argumentaram que a taxa de mudança na política pública normalmente ocorre lenta e gradualmente. No entanto, ocasionalmente, a mudança na política pública também pode ocorrer "acentuadamente", "explosivamente" e em um "curto período" devido a uma perturbação externa (como um evento desencadeador), seguida novamente por uma lenta mudança gradual na política (Givel, 2010).

A Teoria do Equilíbrio Pontuado, originalmente adaptada por Baumgartner e Jones em 1993, argumenta que a formulação de políticas nos Estados Unidos é caracterizada por longos períodos de mudança incremental, pontuados por breves períodos de grande mudança de política. Este último ocorre quando os oponentes conseguem criar novas "imagens de políticas" e explorar os múltiplos locais da política característicos dos Estados Unidos. Originalmente desenvolvido para explicar mudanças na legislação, esse arcabouço foi expandido para incluir análises muito sofisticadas de mudanças de longo prazo nos orçamentos do governo federal (Sabatier, 2007).

A Teoria do Equilíbrio Pontuado, segundo Jones e Baumgartner (2012), nasceu da insatisfação com os modelos de processos políticos que enfatizavam a estabilidade, as regras, o ajuste incremental e o "impasse", enquanto ocorria a mudança na política muitas vezes desarticulada, episódica e nem sempre previsível. Nos primeiros modelos de processos de políticas, desenvolvidos principalmente nas décadas de 1950 e 1960, a tomada de decisões era considerada como incremental, os subsistemas pareciam eternos e a ordem política era estável. Para os autores, nada é resolvido na investigação científica, nem deveria ser. De fato, o sucesso do conceito pode estar em sua obsolescência futura, porque novas formas de pensar devem ser capazes de incorporar na Teoria do Equilíbrio Pontuado uma maneira mais ou menos transparente.

O processo de formulação de políticas públicas é complexo uma vez que envolve inúmeras variáveis ideológico partidárias, institucionais e econômicas: problema; agenda; alternativas; propostas; decisões; interesses; conflitos; dados; 
estimativas; análises de custo-benefício; custo-eficiência e de risco; sustentação do crescimento econômico; restrições orçamentárias; grau de investimento local; atuação de lobbies etc. Considerando que avaliar o universo das variáveis é inviável, torna-se necessário encontrar uma maneira de trabalhar com o melhor modelo, equilibrando a parcimônia (menor quantidade de variáveis explicativas) e o poder explicativo. A escolha de uma teoria e a utilização de indicadores (proxies) para avaliar as políticas públicas representam alternativas disponíveis. A Teoria do Equilíbrio Pontuado, ao explicar a estabilidade e a mudança na formulação de políticas públicas com as contribuições dos cientistas políticos reúne os pressupostos básicos para analisar a política orçamentária dos governos no Brasil (federal, estadual, distrital e municipal).

\subsection{Estudos Empíricos sobre as Teorias do Equilíbrio Pontuado e Incremental}

Existem na literatura estudos empíricos que abordam a Teoria do Equilíbrio Pontudo e a Teoria Incremental nas diversas áreas de governo. A seguir são apresentados alguns destes estudos, visando contribuir com a presente pesquisa.

Jordan (2003) estudou as decisões de natureza orçamentária dos níveis de governo locais (cidades) dos anos fiscais de 1965 a 1992 do censo do relatório anual dos Estados Unidos. Os resultados evidenciam que algumas funções orçamentárias (saneamento, edifícios públicos etc.) são mais propensos a pontuações e, portanto, têm uma agenda menos estável. O significado prático da extensão da Teoria do Equilíbrio Pontuado ao orçamento do governo local são: planejamento, previsão e processo de agendamento.

Hegelich, Fraune e Knollmann (2014) utilizaram dados da política de energia nuclear nos Estados Unidos para analisar como mudanças orçamentárias decisivas em um subsistema de políticas específicas podem estar ligados ao Congresso e ao Presidente. As análises dos dados foram realizadas com as técnicas da análise de cluster, análise de componentes principais e a regressão do modelo linear generalizado (GLM). Os resultados foram capazes de prever mudanças orçamentárias na política de energia nuclear sem violar as premissas da Teoria do Equilíbrio Pontuado.

Ibrahim (2016) testou a Teoria Incremental nos orçamentos dos Emirados Árabes Unidos (EAU) para o período de 1972 a 2010. Os resultados confirmaram o uso do orçamento incremental. Os tomadores de decisão consideram a receita orçamentária do ano anterior como um fator importante para determinar o orçamento do ano seguinte. A inflação, a industrialização, o aumento das demandas por serviços e as mudanças nas prioridades impactaram de forma significativa o processo orçamentário. Na pesquisa, Ibrahim (2016) utilizou três modelos incrementais: o modelo de magnitude de mudança mostrou que a maioria das mudanças está dentro do limiar incremental de $\pm 30 \% ; 11 \%$ das mudanças foram decrementais e 7\% como não incrementais.

Chan e Zhao (2016) analisaram os gastos governamentais regionais (províncias chinesas) do Anuário Estatístico da China publicado pelo Escritório Nacional de Estatísticas da República Popular da China de 1996 a 2013 para verificarem situações de estabilidade e mudanças bruscas. Para os autores, o equilíbrio pontuado surge em estados autoritários porque os funcionários têm pouca exposição à informação, o que prejudica sua capacidade e incentivo 
para fazer ajustes frequentes ao status quo. Os resultados estenderam o equilíbrio pontuado a contextos não democráticos e abrem direções promissoras para futuros estudos comparativos.

Fittipaldi, Costa e Araújo (2017) analisaram se a abordagem incrementalista pode explicar o comportamento do gasto social (funções de governo: Assistência Social; Cultura; Educação; Previdência Social; Saneamento e Saúde) brasileiro no período de 1995 a 2014. Os autores utilizaram medidas de desigualdade para a identificação da dispersão temporal da variável de interesse, bem como projeções do gasto social no médio prazo a partir da utilização de modelo dinâmico autorregressivo integrado e de média móvel (ARIMA). Os resultados foram que o gasto social apresentou um padrão incremental e que essa característica se reproduzirá no médio prazo.

Carvalho (2018) analisou o comportamento de estabilidade e mudança na execução orçamentária da União (Governo Federal Brasileiro), entre 1980 e 2014, das despesas por funções de governo por meio do orçamento federal. Os resultados demonstraram que as maiores amplitudes de variações ocorreram nos anos de 1986, 1989 e 1990, coincidindo com períodos de significativas mudanças institucionais. Da mesma forma, a redução na amplitude das variações observadas a partir de 1996 pode indicar alinhamento com a estabilização monetária como fator institucional que contribui para o equilíbrio da execução orçamentária. Para o autor, ficou perceptível um padrão de equilíbrio com interrupções, corroborando a hipótese central de que a Teoria do Equilíbrio Pontuado é válida para analisar o comportamento das variações orçamentárias no Brasil.

As pesquisas apresentadas na revisão da literatura destacam as Teorias Incremental e a do Equilíbrio Pontuado como teorias de suporte para as análises das variações das implementações das políticas orçamentárias em países democráticos (Estados Unidos), autoritários (China) e monarquias árabes (Emirados Árabes Unidos - EAU). Existem também, no Brasil (multipartidarismo), alguns estudos orçamentários que utilizaram as duas teorias. Empiricamente analisando as variações das implementações orçamentárias, os testes de normalidade ratificam a Teoria Incremental e o contrário (a não normalidade), a Teoria do Equilíbrio Pontuado. Contudo, a Teoria do Equilíbrio Pontuado tem como hipótese central as análises da estabilidade e das variações pontuadas (atípicas) nas execuções das políticas públicas orçamentárias, mas como foi observado no estudo de Ibrahim (2016), a Teoria Incremental pode ser utilizada como suporte isolado nas análises.

Os orçamentos públicos no Brasil, são de forma geral, elaborados de forma incremental, ou seja, utilizam-se os dados do orçamento do ano anterior e acrescenta projeções e estimativas de receitas e despesas para o novo orçamento. A Emenda Constitucional n 95, de 15 de dezembro de 2016 (Brasil, 2016) convalida para o Governo Federal essa metodologia. A emenda instituiu novo regime fiscal em que, de forma geral, os gastos públicos federais por 20 anos são atualizados pelos índices de preços ao consumidor. Nesta perspectiva, utilizar a Teoria Incremental ou somente a Teoria do Equilíbrio Pontuado servirá para compreender como, de fato, é realizada a política orçamentária brasileira. 


\subsection{Hipóteses do Estudo}

Diversos estudos abordam fatores que podem determinar as relações (associações) com a política orçamentária dos países. Existem, também estudos que explicam esses fatores. A seguir são apresentados alguns destes estudos para deduzir as hipóteses que serão testadas.

\subsubsection{Receita Arrecadada}

As fontes de financiamento das despesas públicas no Brasil são classificadas por categoria econômica: receitas correntes para custear as despesas correntes (custeios) e as receitas de capital para aplicar nas despesas de capital (investimentos). As categorias econômicas representam a forma como os recursos são arrecadados: receitas correntes são os recursos arrecadados diretamente da população (impostos, taxas e contribuições) e receitas de capital, como aquelas provenientes de empréstimos e financiamentos e de alienação de bens públicos.

O equilíbrio entre as receitas e as despesas, além da necessidade de haver uma compatibilidade na economia privada e pessoal, é determinado no setor público brasileiro na Lei $n^{\circ} 4.320$, de 17 de março de 1964 (Brasil, 1964), em que se exige que seja mantido, durante o exercício, na medida do possível, o equilíbrio entre a receita arrecadada e a despesa realizada. A Lei de Responsabilidade Fiscal (Brasil, 2000) determina que haja equilíbrio entre as receitas e despesas por ocasião da determinação das diretrizes para elaborar o orçamento público.

A relação entre a receita e os gastos do governo tem sido um tópico importante na economia pública, dada sua relevância para a política, especialmente no que diz respeito ao déficit orçamentário (Mehrara \& Rezaei, 2014). Segundo Rosoiu (2015), a relação entre as receitas e os gastos governamentais é bidirecional. A questão que se impõe é o quanto o estado deve aumentar as despesas em relação às receitas para que o bem-estar social não seja afetado.

As relações entre as despesas e as receitas foram abordadas empiricamente por Ukwueze (2015) e Lojanica (2015). Ukwueze (2015) investigou os determinantes do tamanho da despesa pública na Nigéria. Os resultados demonstraram que o investimento privado, a taxa de crescimento da produção e a receita do governo e a mudança populacional são determinantes do tamanho do setor público. As mudanças na taxa de crescimento populacional geram alterações na distribuição etária e essa tendência se reflete nos gastos com educação, cuidados com os idosos, defesa, proteção policial, proteção contra incêndio etc. Para o autor, o estudo apoia a Lei de Wagner de que o crescimento da renda nacional aumenta o tamanho do setor público.

Lojanica (2015) analisou as ligações entre as receitas do governo e as despesas do governo na República da Sérvia. Com base nos resultados empíricos obtidos, as implicações políticas devem ser orientadas para a redução das despesas do governo a longo prazo, uma vez que, do ponto de vista da estabilidade e crescimento da economia sérvia, os níveis dos gastos são insustentáveis e as tendências crescentes de déficits fiscais são inaceitáveis, assim como a tendência ascendente da dívida do governo e do setor privado. 
Na perspectiva desses estudos e nas questões impostas pela legislação brasileira, formula-se a seguinte hipótese:

Hipótese 1 (H1): A receita arrecadada tem efeito positivo (mais recursos poderão resultar em melhorias no atendimento dos serviços públicos) e significativo (relevante) com a execução da despesa orçamentária.

\subsubsection{Número de Habitantes (população)}

Os efeitos do aumento do número de habitantes (população) em relação às finanças públicas foram estudados por diversos autores. Bezdek, Dybczak e Krejdl (2003) realizaram projeções de longo prazo para avaliarem a sustentabilidade das finanças públicas relacionadas com 0 aumento da população na República Tcheca em comparação com outros países da Organização para a Cooperação e Desenvolvimento Econômico (OCDE). A projeção indica que o efeito cumulativo do envelhecimento da população no mercado de trabalho e nas finanças públicas será profundo. Dadas as tendências demográficas desfavoráveis, os decisores políticos terão que contemplar como lidar com as pressões sobre os gastos públicos decorrentes do envelhecimento populacional, principalmente na saúde.

Wong e Carvalho (2006), ao estudar os motivos da transição na estrutura etária no Brasil (declínio da fecundidade, alterações nos padrões de sobrevivência, fluxos migratórios, crescimento diferenciado da população, qualificação da força de trabalho etc.), concluíram que se a transferência per capita do governo for mantida constante, a diferença entre receitas e despesas aumentará, provocando um insuportável déficit fiscal. A crise causada pelo envelhecimento da população e o sistema irracional previdenciário devem ser matéria de discussão na sociedade brasileira.

Miller e Castanheira (2013), ao estimarem a influência do envelhecimento populacional nas despesas no Brasil, no período de 2005 a 2050, verificaram o provável aumento no gasto público nas próximas décadas, contrastando diferentes tendências no gasto em educação, saúde e previdência social. Para os autores, a despesa pública iniciará um aumento rápido e sustentado com duração de várias décadas. As necessidades crescentes de investimentos em educação irão competir com o crescente e sustentável aumento de demanda na saúde pública e na previdência social originado do considerável crescimento da proporção de idosos na população brasileira.

Zokalj (2016) analisou o impacto do envelhecimento da população nas finanças públicas na União Europeia. O estudo concluiu que um aumento na população jovem tem um impacto significativo (relevante) apenas no gasto em saúde e o envelhecimento da população tem maior impacto positivo (aumento) sobre a despesa pública global em comparação com a receita total do governo.

Em consonância com os estudos de Bezdek, Dybczak e Krejdl (2003), Wong e Carvalho (2006), Miller e Castanheira (2013) e de Zokalj (2016), formulou-se a seguinte hipótese:

Hipótese 2 (H2): O número de habitantes (população) tem efeito negativo (aumento de despesa em desequilíbrio com a receita - diminuição no atendimento por parte do Estado em serviços públicos) e significativo (relevante) 
com a execução orçamentária da despesa (proxies variações pontuadas e/ou incrementais).

\subsubsection{Produto Interno Bruto}

A soma dos bens e serviços produzidos em um país durante certo período representa o Produto Interno Bruto (PIB), assim, os investimentos das empresas e os gastos do governo impulsionam o PIB. O PIB é um dos principais indicadores do potencial da economia de um país. Enquanto o PIB nominal é calculado a preços correntes, ou seja, no ano em que o produto foi produzido e comercializado, o PIB real é calculado a preços constantes, em que é escolhido um ano-base para o seu cálculo, eliminando, assim, o efeito da inflação.

Bird (1971) esclarece que a dinâmica de crescimento dos gastos públicos leva à chamada Lei de Wagner, ou Lei dos Dispêndios Públicos Crescentes, que afirma que a elevação da renda nacional induz as despesas governamentais a crescerem mais que proporcionalmente, ou seja, existe uma tendência de longo prazo de ampliação da parcela do produto dedicada às despesas públicas. Isto significa que existe uma elasticidade-renda da demanda por bens e serviços providos pelo Estado maior que a unidade.

Sakurai (2009), ao analisar os ciclos políticos nas funções orçamentárias dos municípios, observou que existe uma influência do PIB nacional sobre o comportamento das despesas dos municípios brasileiros. Para o autor, alguns casos são esperados, como ocorre nos casos das funções Agricultura, Transporte, Assistência e Previdência, Legislativa e Educação e Cultura, visto que as despesas destas funções são positivamente relacionadas com o ciclo econômico. Por sua vez, de forma contra intuitiva, as despesas das funções Saúde e Saneamento, Comunicações e Habitação e Urbanismo tendem a decrescer em anos de expansão da produção agregada. Embora seja complexo definir uma razão concreta para tal fenômeno, estes resultados parecem indicar que o próprio comportamento do nível de renda nacional tende a influenciar a forma pela qual os recursos são alocados pelas prefeituras brasileiras, ou seja, períodos de expansões econômicas nem sempre estão associados a maiores gastos públicos de maneira generalizada.

Rosenthal e Wolfson (2013) não encontraram significância estatística do Produto Interno Bruto per capita em relação a variável dependente (uso dos orçamentos pelo governo), ao examinarem vários determinantes da implementação orçamentária em Israel. As principais variáveis analisadas de choques macroeconômicos foram: taxa de desemprego, o Índice Gini como fator de desigualdade socioeconômica e a taxa de inflação.

Silva e Triches (2014) analisaram os efeitos dos gastos governamentais sobre o PIB da economia brasileira ao longo do período de 1980 a 2005. Os resultados demonstraram que as despesas públicas em Comunicação, Transporte, Saúde e Saneamento se mostraram como gastos produtivos por estimular o crescimento da renda. Para os autores, as atividades governamentais podem elevar o nível do produto total de forma direta ou indireta por meio da interação com o setor privado e o financiamento dos gastos públicos via impostos pode provocar distorções e ineficiência na alocação de recursos. 
Magazzino, Giolli e Mele (2015) argumentam que a relação entre a despesa pública e o PIB é debatida na literatura econômica por dois lados. No primeiro, a despesa pública é vista como um fator exógeno, que pode ser usado como um instrumento político para influenciar o crescimento. No outro lado, a despesa pública é vista como um instrumento endógeno ou como um resultado e não uma causa de crescimento na renda nacional. Para os autores, no longo prazo, um aumento de 1 ponto percentual no PIB tende a determinar um aumento na relação despesa pública / PIB entre 0,01\% e 0,62\%.

Zaed (2017) esclarece que os resultados a curto e longo prazo deixaram claro que há uma diferença no resultado dos estudos aplicados, em que se constata que cada um suporta uma relação da Lei de Wagner, no sentido de que há uma tendência causal do PIB real para os gastos do governo. $O$ crescimento econômico leva a uma demanda agregada maior, o que, por sua vez, aumenta a necessidade de aumentar os gastos governamentais bem como os recursos disponíveis para o setor governamental financiar o aumento dos gastos pelos recursos adicionais resultantes do crescimento econômico.

Jaén-García (2018), ao estudar diversos problemas teóricos e práticos relacionados à Lei de Wagner sobre o crescimento do gasto público, verificou que a lei é rejeitada na Espanha com base na crença de que há outras variáveis, além do PIB, que influenciam o crescimento do gasto público. Para o autor, grande parte do aumento dos gastos públicos na Espanha tem sido causado pelo déficit, a ponto de, em um período de seis anos, a dívida pública subiu de $60 \%$ do PIB para 100,63\%. Esse aumento no déficit e na dívida não foi incorrido pela melhoria do estado de bem-estar social, com a correspondente criação de empregos em Saúde e Educação, mas, em contraste marcado, os gastos públicos foram restringidos juntamente com o emprego nesses dois setores.

Observa-se que não existe consenso nos estudos sobre o PIB em relação aos gastos do governo (Bird, 1971; Zaed, 2017; Jaén-García, 2018). Contudo, considerando a despesa pública como um fator exógeno ou endógeno do crescimento da renda nacional (Magazzino, Giolli \& Mele, 2015), assim, delineiase a terceira hipótese a ser testada:

Hipótese 3 (H3): O Produto Interno Bruto tem um efeito positivo (crescimento das atividades econômicas poderá resultar em mais aplicações) e significativo (relevante) sobre a execução orçamentária da despesa do Governo Federal.

\subsubsection{Competição Política Partidária}

A competição política interessa (em todos os sentidos), acima de tudo, a todos os agentes situados no topo da hierarquia social, ou melhor, às diferentes frações das classes superiores. As organizações políticas podem impedir parcialmente a lógica seletiva dominante da competição política (Gaxie, 2012). Tarouco e Dantas Neto (2017) esclarecem que a competição política é um elemento fundamental da democracia, podendo se apresentar - em diferentes países, ou diferentes momentos da história política de um país - com variados graus de institucionalização. Pode ser centralmente um fenômeno de politics, mas varia o grau em que incorpora, também, traços de polity. Formatos e padrões de competição política, na medida em que se estabilizem, podem ter papéis estruturantes da política e condicionantes das 
estratégias dos atores políticos, ao tempo em que também constituem resultado institucional da interação das estratégias.

Ferris, Park e Winer (2008) analisaram as contribuições da economia e da política para a evolução da despesa pública pelo Governo do Canadá em período de mais de 130 anos. Os resultados demonstraram que a competição política é central para a previsão de que os equilíbrios das escolhas políticas estejam sintonizados com os interesses dos eleitores. Uma redução no grau de competitividade política pode permitir que agentes políticos e/ou burocráticos desviem recursos públicos para usos privados ou partidários, aumentando a despesa pública acima do nível previsto com base apenas nos fundamentos econômicos.

Hobolt e Klemmensen (2008) verificaram a capacidade de resposta das promessas da política (discursos) e ações da política (gastos públicos) na GrãBretanha, Dinamarca e Estados Unidos no período de 1970 a 2005. Os resultados demonstraram que a capacidade de resposta efetiva é maior nos Estados Unidos do que nos sistemas parlamentares da Dinamarca e da Grã-Bretanha. Altos níveis de incerteza sobre as chances de reeleição parecem ter um efeito favorável na capacidade de resposta do governo. Quando a popularidade do governo é baixa, a capacidade de resposta às preferências de questões públicas é maior. Quanto mais difícil a competição por votos e políticas, maior a probabilidade da população se beneficiar dos gastos públicos e menos oportunidade para os interesses próprios.

Adit e Ełerovic (2011), ao analisarem a competição política, a participação eleitoral e as finanças públicas em vários países da América Latina em relação ao tamanho do governo, verificaram que as reformas que aumentam a competição política tendem a limitar o tamanho do governo, enquanto que as reformas que aumentam a participação política tendem a aumentar o tamanho do governo. Para os autores, a competição política é certamente um aspecto da democracia, mas a maioria das definições também se refere a alguma noção de participação eleitoral (por exemplo, sufrágio universal) e liberdades civis. A intensificação da competição política experimenta uma queda nas despesas do governo e na tributação em relação ao produto interno bruto.

Silva (2017), ao estudar os ciclos do presidencialismo de coalizão (composição partidária majoritária e representação estadual) e seus determinantes político-econômicos no Brasil (taxa de inflação, PIB e a popularidade presidencial), observou-se que a diminuição do PIB causa diminuição do apoio parlamentar, bem como uma maior popularidade presidencial causa maior disciplina da coalizão. A relação entre apoio parlamentar e inflação não foi confirmada. Além disso, ressalta-se as tendências de oscilações das variáveis e sua coincidência com a ocorrência de crises políticas. Os resultados apontam a influência de fatores político-econômicos sobre o apoio parlamentar da coalizão.

Thomson et al. (2017) analisaram o cumprimento das promessas de campanhas eleitorais em doze países. Os resultados demonstraram que os maiores percentuais de cumprimento ocorreram no Reino Unido, Suécia, Portugal, Espanha e Canadá com a maioria dos quais governava-se com partido único. Nos países de governos em coalizões (Alemanha, Holanda, Áustria, Bulgária, Irlanda e Itália) ocorreram percentuais mais baixos. Nos Estados Unidos da 
América o cumprimento das promessas ficou na extremidade superior dos governos de coligação.

A competição política afeta a performance econômica de um país ao bloquear políticas ineficientes e pode levar os partidos a selecionarem os candidatos. A oposição partidária dos chefes do Poder Legislativo em relação ao do Poder Executivo pode afetar a execução orçamentária (executar mais ou menos despesas), independentemente das diferenças existentes nas políticas dos países. Considerando os estudos de Ferris, Park e Winer (2008), Hobolt e Klemmensen (2008), Adit e Eterovic (2011), Gaxie, 2012; Silva, 2017; Thomson et al., 2017 e Tarouco e Dantas Neto (2017), reporta-se a quarta hipótese de pesquisa investigada:

Hipótese 4 (H4): A oposição partidária dos Presidentes da Câmara dos Deputados e do Senado Federal ao Presidente da República Federativa do Brasil (competição política) tem efeito negativo (obstrução aos programas de governo) e significativo (relevante) com a execução da despesa orçamentária.

\section{PROCEDIMENTOS METODOLÓGICOS}

Após o desenvolvimento das hipóteses a partir da literatura, seguiu-se as seguintes etapas: (i) definição das variáveis e do banco de dados (item 3.1); (ii) escolhas dos testes estatísticos para as análises (item 3.2); (iii) efetivação dos testes estatísticos; (iv) análises dos resultados (item 4). Foi definido também que a investigação utiliza a estratégia da pesquisa de avaliação de resultados e o método empírico-analítico.

A avaliação de resultados, segundo Martins e Theóphilo (2009), é uma estratégia empírica aplicada para avaliar programas, projetos, políticas etc. 0 método empírico-analítico (arquivo/empirista - banco de dados) corresponde à utilização de técnica de coleta, tratamento e análise de dados com métricas quantitativas. Matias-Pereira (2012) esclarece que nesse método, o processo de validação da prova científica é feito por meio de testes dos instrumentos, graus de significância e sistematização das definições operacionais.

\subsection{Variáveis e Banco de Dados}

A Tabela 1 define as variáveis utilizadas no estudo (dependentes e explicativas). 


\section{Tabela 1}

Definição das variáveis

Variáveis

$Y=$ dependentes: tipo de orçamento (variável de referência: 0 - Orçamento Pontudo).

\begin{tabular}{|c|c|c|}
\hline Explicativas (independentes) & Descrições & Hipóteses \\
\hline $\begin{array}{l}\text { X1 = Receita Arrecadada (log) } \\
\text { (REC) }\end{array}$ & $\begin{array}{l}\text { Logaritmo da receita orçamentária } \\
\text { arrecadada }\end{array}$ & $\mathrm{Hl}(+)$ \\
\hline X2 = População (log) (POP) & Logaritmo da estimativa de população & $\mathrm{H} 2(-)$ \\
\hline$X 3=$ PIB real per capita (PIB) & Produto Interno Bruto real per capita & $\mathrm{H} 3(+)$ \\
\hline $\begin{array}{l}\text { X4 e X5 = Competição política } \\
\text { partidária (oposição partidária) } \\
\text { - variável de referência: } 0- \\
\text { Partido do Presidente da } \\
\text { República. }\end{array}$ & $\begin{array}{l}\text { Partido Político do Presidente da } \\
\text { República, do Presidente do Senado } \\
\text { Federal (SENADO) e do Presidente da } \\
\text { Câmara dos Deputados Federais } \\
\text { (CAMARA): variáveis dummies: Partido do } \\
\text { Presidente (0) e contrário (1). }\end{array}$ & H4 (-) \\
\hline
\end{tabular}

Fonte: dados da pesquisa.

As variáveis binárias dependentes (Tabela 1) se referem ao aspecto temporal da execução das despesas orçamentárias da República Federativa do Brasil (Poder Executivo) dos anos de 1980 a 2018. Este período foi escolhido pela disponibilidade de dados da execução orçamentária do Governo Federal por ocasião da elaboração desta investigação (abril de 2019). A finalidade dessas variáveis é determinar pelas variações percentuais da execução orçamentária, o tipo de orçamento: pontuado ou incremental (Tabela 2).

Os dados da execução orçamentária da despesa foram atualizados para o dia 31 de janeiro de 2019 pela variação do IGP-DI (Índice Geral de Preços Disponibilidade Interna) da Fundação Getúlio Vargas (FGV). O IGP-DI é utilizado pela Secretaria do Tesouro Nacional (STN) para atualizar os valores de séries históricas de receitas e despesas. As atualizações foram realizadas com o apoio do sítio eletrônico Cálculo Exato.com (Cálculo Exato, 2019). Os dados foram extraídos do sítio eletrônico da Secretaria do Tesouro Nacional - STN (STN, 2019) no mês de abril de 2019. A Secretaria do Tesouro Nacional (STN), vinculada ao Ministério da Economia, é responsável pela publicação da consolidação das contas públicas no Brasil. Os dados sobre o número de habitantes (população) e - Produto Interno Bruto real per capita foram extraídos do sítio eletrônico do Instituto Brasileiro de Geografia e Estatística (IBGE, 2019).

Os Presidentes da República Federativa do Brasil no período de 1980 a 2018, foram dos Partidos: Aliança Renovadora Nacional (ARENA), Partido do Movimento Democrático Brasileiro (PMDB), Partido da Reconstrução Nacional (PRN), Partido da Social Democracia Brasileira (PSDB) e Partido dos Trabalhadores (PT). A listagem dos Partidos Políticos dos ex-presidentes da República Federativa do Brasil foi extraída do sítio eletrônico da Biblioteca da Presidência da República (2019), dos ex-presidentes da Câmara dos Deputados Federais do sítio eletrônico da Câmara dos Deputados (2019) e dos ex-presidentes do Senado Federal do sítio eletrônico do Senado Federal (2019). 


\subsection{Análises de Dados}

O estudo adota os percentuais de Jordan (2003) para demonstrar aqueles considerados extremos (atípicos), os quais necessitam de análises complementares para verificar os possíveis motivos das mudanças na execução orçamentária: positivos iguais ou superiores a $35 \%$ e/ou negativos de $25 \%$ ou mais como variação pontuada (Teoria do Equilíbrio Pontuado). As demais variações são consideradas incrementais - estabilidade (Teoria Incremental). Os Testes de Kolmogorov-Smirnov e Shapiro-Wilk foram utilizados para testar a normalidade ou não das variações das execuções orçamentária das despesas com o objetivo de identificar no histograma se a distribuição é normal ou leptocúrtica (distribuição mais afunilada com um pico mais alto do que a distribuição normal - possui caudas pesadas e é mais achatada). A utilização desses testes segue as orientações de Fávero et al. (2009).

A associação ou não das variáveis explicativas com as variáveis dependentes binárias foi realizada com a modelagem da regressão do Modelo Linear Generalizado (MLG ou GLM em inglês: Generalized Linear Models) regressões exponenciais. Os componentes para qualquer GLM são: o componente aleatório (distribuição de probabilidade); o componente sistemático (especificação das variáveis explicativas) e a função de ligação ((n ou $g(\mu))$, que especifica a ligação entre os componentes aleatórios e sistemáticos.

Um Modelo Linear Generalizado (MLG ou GLM) é definido da seguinte forma:

$$
\eta_{1}=a+\beta_{1} \cdot x_{1 i}+\beta_{2} \cdot x_{2 i} \quad \ldots+\beta_{k} \cdot x_{k i}
$$

em que: $\eta$ é conhecido por função de ligação canônica; a representa a constante; $\beta_{j}(j=1,2, \ldots ., k)$ são os coeficientes de cada variável explicativa e correspondem aos parâmetros a serem estimados; $X_{j}$ são as variáveis explicativas (métricas ou dummies) e os subscritos i representam cada uma das observações da amostra em análise $(i=1,2, \ldots, n$, em que $n$ é o tamanho da amostra.

Não existem restrições (pressupostos) para a utilização do GLM, exceto quanto ao tipo de distribuição de probabilidade utilizada (componente aleatório), a especificação das variáveis (componente sistemático) e a escolha da função de ligação (Mccullagh \& Nelder, 1989; Breslow, 1996; Lindsey, 1997; Olsson, 2002; Liang, 2002; Swan, 2006; Agresti, 2007; Cordeiro \& Demétrio, 2008; Myers et al., 2010; Fávero, 2015; Abdulkabir et al., 2015). A distribuição utilizada foi a de Bernoulli em que as variáveis podem assumir dois valores numéricos 0 ou 1 , em que 1 corresponde a um evento e 0 corresponde a um não evento. A distribuição de Bernoulli é uma distribuição discreta que está relacionada com várias distribuições, como a distribuição binomial, geométrica e binomial negativas. Ela representa o resultado de um ensaio. Os cálculos estatísticos foram realizados com o SPSS 21.

\section{RESULTADOS E DISCUSSÕES}

A Tabela 2 apresenta as variações percentuais das despesas orçamentárias do período de 1980 a 2018. As variações foram calculadas para 
definir as variáveis dependentes da execução orçamentária com base nas Teorias Incremental e Equilíbrio Pontuado.

\section{Tabela 2}

Variações percentuais das despesas orçamentárias (1980-2018)

\begin{tabular}{cccccccc}
\hline Anos & $\%$ & Anos & $\%$ & Anos & $\%$ & Anos & $\%$ \\
\hline $1981^{*}$ & $-9,80$ & $1991^{*}$ & $-58,69$ & $2001^{*}$ & $-11,30$ & $2011^{*}$ & 27,48 \\
$1982^{*}$ & 4,83 & $1992^{*}$ & 25,75 & $2002^{*}$ & $-1,46$ & $2012^{*}$ & 24,84 \\
$1983^{*}$ & $-5,34$ & $1993^{*}$ & 15,71 & $2003^{*}$ & 5,76 & $2013^{*}$ & 19,38 \\
$1984^{*}$ & $-4,95$ & $1994^{*}$ & 8,18 & $2004^{*}$ & $-5,28$ & $2014^{*}$ & 53,96 \\
$1985^{*}$ & 18,49 & $1995^{*}$ & 7,58 & $2005^{*}$ & 15,01 & $2015^{*}$ & 19,84 \\
$1986^{*}$ & 73,48 & $1996^{*}$ & 7,54 & $2006^{*}$ & 4,33 & $2016^{*}$ & 21,42 \\
$1987^{*}$ & $-9,29$ & $1997^{*}$ & 25,59 & $2007^{*}$ & $-5,59$ & $2017^{*}$ & 4,35 \\
$1988^{*}$ & 25,14 & $1998^{*}$ & 23,26 & $2008^{*}$ & $-37,89$ & $2018^{*}$ & 6,68 \\
$1989^{*}$ & 135,34 & $1999^{*}$ & 5,68 & $2009^{*}$ & 11,67 & & \\
$1990^{*}$ & 43,40 & $2000^{*}$ & $-7,94$ & $2010^{*}$ & 21,89 & & \\
\hline
\end{tabular}

Legenda: * variações 1981/1980 e sequências.

Fonte: dados da pesquisa.

O ano inicial de 1980 não aparece na Tabela 2, haja vista que representa o ponto de partida (base) para demonstrar as variações. Os cálculos foram realizados dividindo o valor da variável do ano seguinte pelo anterior (1981/1980 e sequências), demonstrados em números decimais multiplicados por 100. Desse modo, os valores representam os números índices de percentagem de variação positiva ou negativa (fórmula no Excel $=((x 2 / x 1)-1) * 100)$.

Destacam na Tabela 2 como variações bruscas atípicas (Teoria do Equilíbrio Pontuado), as execuções das despesas orçamentárias de 1986/1985 $(73,48 \%)$ e 1989/1988 (135,34\%), ambas no Governo de José Sarney; 1990/1989 $(43,40 \%)$ e 1991/1990 (-54,69\%), ambas no Governo de Fernando Collor; $2008 / 2007$ (-37,89\%) no Governo de Luiz Inácio Lula da Silva e de 2014/2013 (53,96\%), no Governo de Governo Dilma Rousseff.

O Governo de José Sarney foi marcado pelo período de alta inflação e de diversos planos econômicos (Plano Cruzado, Bresser e Verão). O governo tentou controlar os gastos públicos, conter a forte inflação e renegociar a dívida externa. As tentativas de melhorar a economia podem ser consideradas como explicações para ter ocorrido as variações atípicas no Governo de José Sarney. O Governo de Fernando Collor também foi marcado pelo combate a hiperinflação e com planos econômicos que incluíram ações de impacto como: redução da máquina administrativa com a extinção ou fusão de ministérios e órgãos públicos, demissão de funcionários públicos e o congelamento de preços e salários. As variações pontuadas no Governo de Fernando Collor também podem ser esclarecidas pela forma de seu governo.

O ano de 2008 foi um dos mais intensos na economia mundial, com resultados negativos em bancos, falências, planos bilionários de governo, alta do dólar e crises econômicas. A variação pontuada negativa de -37,89\% no Governo de Luiz Inácio Lula da Silva pode ser explicada por reflexos da economia internacional no Brasil. No Governo de Governo Dilma Rousseff a variação 
pontuada $(53,96 \%)$ pode ser explicada pelo ano eleitoral e pela realização da Copa do Mundo de Futebol de 2014 no Brasil

A Tabela 3 apresenta os resultados dos testes de normalidade das despesas orçamentárias, do período de 1980 a 2018.

\section{Tabela 3}

Teste de normalidade das despesas orçamentárias (1980-2018)

\begin{tabular}{lcccccc} 
& \multicolumn{3}{c}{ Kolmogorov-Smirnov } & \multicolumn{3}{c}{ Shapiro-Wilk } \\
\cline { 2 - 7 } Vatatística & Df & Sig. & Estatística & df & Sig. \\
Variacs & 0,213 & 38 & $0,000^{*}$ & 0,838 & 38 & $0,000^{*}$ \\
\hline Curtose: 6,977 & Legenda: * $=$ distribuição leptocúrtica. \\
Lonte: dados da pesquisa.
\end{tabular}

Observa-se na Tabela 3, que os Testes de Kolmogorov-Smirnov e ShapiroWilk apresentam o p-valor $<0,05$ (estatística de curtose de 6,977), o que indica uma distribuição leptocúrtica e comprova a não normalidade da curva de frequência. Isto significa que a política de execução orçamentária das despesas do Governo Federal, no período de 1980 a 2010, apresenta comportamentos de mudanças bruscas (atípicas) e de estabilidade, o que é compatível com a Teoria do Equilíbrio Pontuado.

Estes resultados são corroborados com a pesquisa de Carvalho (2018), embora o autor tenha analisado a execução orçamentária do Governo (19802014) por funções de governo (Legislativa; Judiciária; Administração e Planejamento; Saúde e Saneamento etc.)

A Figura 1 apresenta 0 histograma de frequência das variações percentuais das despesas orçamentárias. Observa-se que a Figura 1 convalida as análises apresentadas na Tabela 3. O histograma possui uma distribuição leptocúrtica (a curva da função de distribuição é mais afunilada com um pico mais alto do que a distribuição normal). Esse resultado confirma a hipótese de True, Jones e Baumgartner (2007), segundo a qual variações orçamentárias anuais apresentam distribuição leptocúrtica, ou seja, uma distribuição com um pico central delgado demonstrando a lógica da estabilidade, ocorrência relativamente baixa de mudanças moderadas e, nas caudas, a ocorrência das pontuações (mudanças bruscas - atípicas) orçamentárias. 


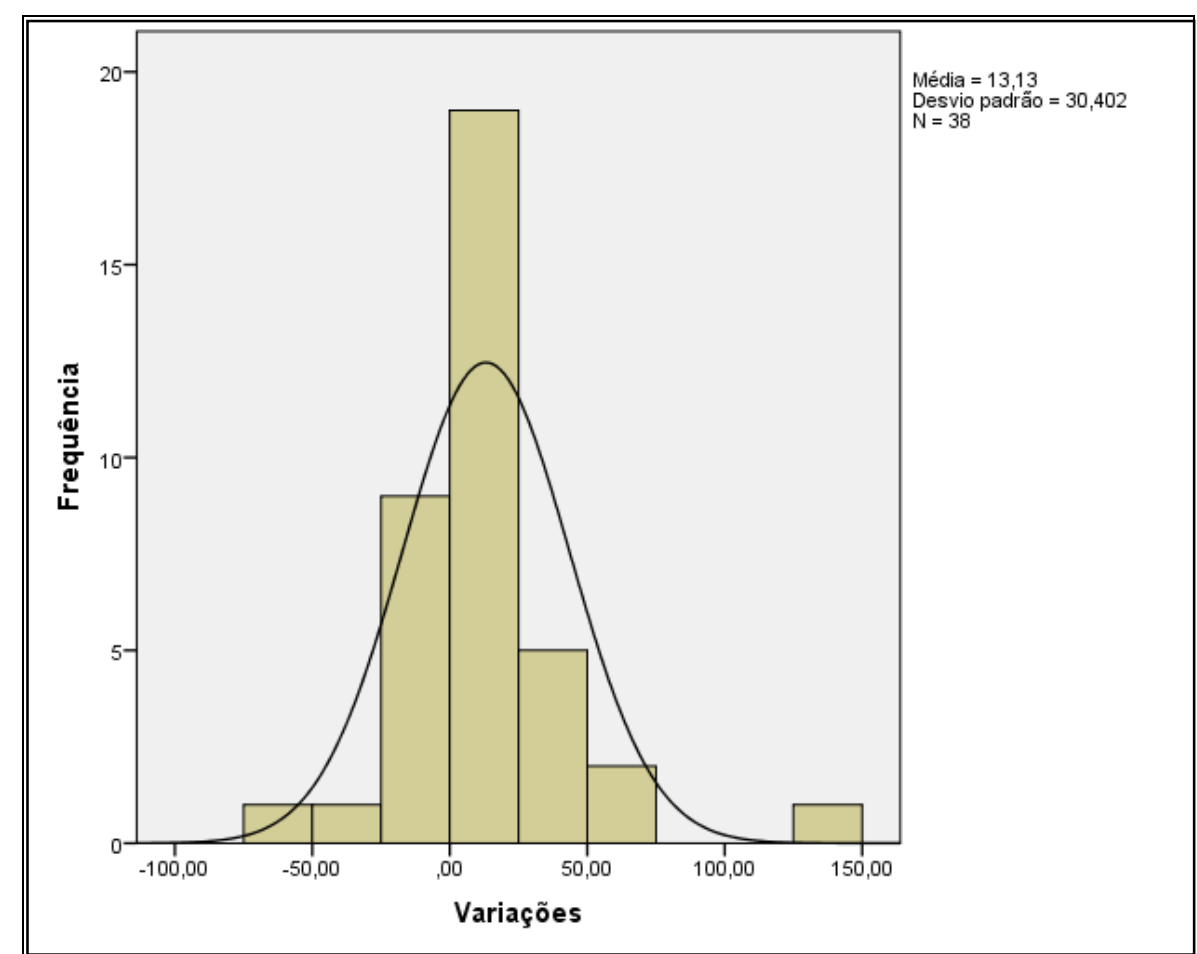

Figura 1 Histograma de frequência das variações das despesas orçamentárias. Fonte: dados da pesquisa.

A Tabela 4 apresenta os resultados da regressão do modelo linear generalizado (GLM). Na regressão robusta foi utilizada a distribuição de Bernoulli com a função de ligação Logit, que é apropriada para a distribuição leptocúrtica (Tabela 3). 
Tabela 4

Resultados da regressão do modelo linear generalizado (GLM)

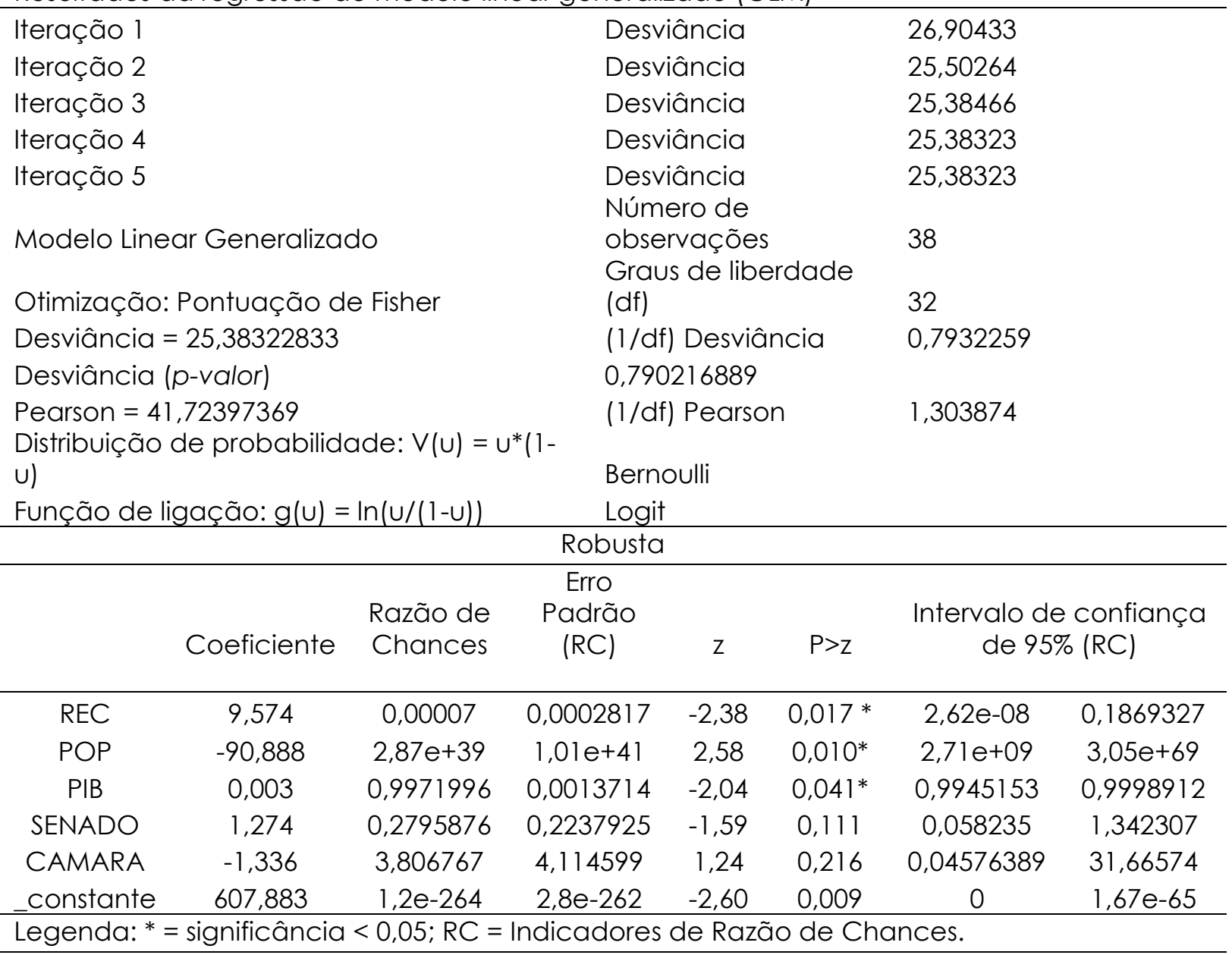

Fonte: dados da pesquisa.

Observa-se na Tabela 4 que as probabilidades de ocorrência (associação com a variação dependente) foram significativas ( $p$-valor $<0,05$ ) para as variáveis Receita Arrecadada (REC), População (número de habitantes - POP) e Produto Interno Bruto per capita (PIB). A razão de chances ou razão de possibilidades também foram significativas por não apresentarem o valor de 1, que indicaria a hipótese de $50 \%$ do evento ocorrer ou não. A Receita Arrecadada (REC) e o Produto Interno Bruto por apresentarem o valor menor que 1, indica uma menor hipótese de o acontecimento acontecer, o que contraria a situação esperada das Hipóteses HI e H3. A variável População (POP) com a razão de chances acima de 1 indica que existe maior possibilidade de o acontecimento acontecer. Este resultado aliado com o sinal negativo do coeficiente corrobora com a situação esperada da Hipótese H2. As variáveis da Hipótese H4 Competição Política Partidária (SENADO e CÂMARA), por apresentarem valor acima do nível de significância de 0,05 $(0,111$ para o Senado e 0,216 para a Câmara), não são analisadas (estatisticamente não é possível realizar inferências).

Analisando as hipóteses do estudo, observa-se que não rejeita a Hipótese 1 (H1) testada na variável Receita Arrecadada (REC) com o p-valor de 0,017 e o coeficiente de 9,574 (sinal esperado positivo). Isto significa que, com o nível de confiança de 95\%, existe um efeito positivo e significativo entre a receita 
arrecadada com a execução da despesa orçamentária, logo, uma maior arrecadação pode aumentar os serviços públicos. Este resultado é corroborado com as pesquisas de Ukwueze (2015) e Lojanica (2015). Contudo, deve-se observar que os níveis de gastos devem ter correlação com o crescimento da economia para não ocorrer déficits fiscais (Lojanica, 2015).

A Hipótese 2 (H2) com a variável número de habitantes (população - POP) com o p-valor de 0,010 e o coeficiente de -90,888 (sinal esperado negativo) não é rejeitada com o nível de confiança de $95 \%$. Esse resultado indica que o número de habitantes (população) tem efeito negativo e significativo com a execução orçamentária da despesa (proxies variações pontuadas e/ou incrementais). $O$ aumento do número de habitantes provoca uma diminuição no atendimento por parte do Estado em serviços públicos, principalmente com o envelhecimento da população (Bezdek, Dybczak \& Krejdl, 2003; Zokalj, 2016).

A variável explicativa Produto Interno Bruto per capita apresentou o $p$-valor de 0,041 e o coeficiente de 0,003, demonstrando o efeito positivo e significativo na execução da despesa orçamentária do Governo Federal. Isto significa que, com o nível de confiança de 95\%, a Hipótese $3(\mathrm{H} 3)$ não é rejeitada. Este resultado difere da pesquisa de Rosenthal e Wolfson (2013), por não encontrarem significância estatística, mas é corroborada com os estudos de Silva e Triches (2014). Embora Sakurai (2009) tenha analisado a relação de gastos por funções orçamentárias dos municípios, o resultado de sua pesquisa encontrou influência do PIB nacional sobre o comportamento das despesas dos municípios brasileiros.

\section{CONSIDERAÇÕES FINAIS}

O processo de formulação de políticas públicas é complexo uma vez que envolve inúmeras variáveis ideológico partidárias, institucionais e econômicas. A política pública orçamentária trata, de forma resumida, da obtenção dos recursos públicos (receitas) para custear os serviços públicos (despesas) em prol do bem-estar da comunidade. A solução de problemas para atender a comunidade contempla inúmeras variáveis: agenda; alternativas; propostas; decisões; interesses; conflitos; atuação de lobbies; análises de custo benefícios etc. Assim, encontrar fatores para os decisores políticos que podem sinalizar de forma prospectiva para solucionar esses problemas é relevante.

Nesta perspectiva, este estudo analisa, dentre um conjunto de fatores, quais foram os determinantes da política de execução orçamentária no Brasil, no perío do de 1980 a 2018. As variações da execução orçamentária de um ano para o outro, com o suporte teórico das Teoria Incremental e Equilíbrio Pontuado, foram a base para determinar os fatores determinantes (associados).

Dentre as teorias utilizadas para analisar a política orçamentária, destaca a Teoria do Equilíbrio Pontuado ao explicar a estabilidade e a mudança na formulação dessas políticas como hipótese central. Formulada para realizar argumentações sobre a formulação de políticas públicas nos Estados Unidos, observa-se que é utilizada por pesquisadores de vários países (China, Etiópia, Nigéria, Brasil etc.). A Teoria Incremental, embora considerada incluída na Teoria do Equilíbrio Pontuado, continua válida para suportar análises de estabilidade de execução orçamentária. 
Este estudo contribui teoricamente para a literatura sobre fatores que podem ser considerados determinantes nas decisões orçamentárias. Empiricamente contribui com a utilização da modelagem da regressão do Modelo Linear Generalizado ao difundir a utilização de regressões exponenciais (distribuição Bernoulli, Binominal, Gama, Poisson, Poisson-Gama, Tweedie etc.). Essas regressões além de apresentarem flexibilidade nas restrições (exceto quanto ao tipo de distribuição), quando se utiliza a regressão robusta, as distorções de pressupostos também são corrigidas. O Modelo Linear Generalizado também inclui a distribuição normal, mas neste caso é obrigatório verificar os pressupostos de linearidade, independência dos erros, normalidade da distribuição dos erros, homocedasticidade e multicolinearidade.

Espera-se estimular mais pesquisas correlatas, considerando que essas discussões são relevantes para a sociedade. Esta investigação não pode fazer inferência sobre a Hipótese $4(\mathrm{H} 4)$, que testou a oposição partidária dos Presidentes da Câmara dos Deputados e do Senado Federal ao Presidente da República (competição política) com efeito negativo e significativo com a execução da despesa orçamentária, considerando que o nível de significância ultrapassou o esperado ( $p$-valor de 0,05 ). Outras pesquisas poderão replicar essa abordagem em Governos Estaduais e Municipais, bem como poderão ampliar a situação da competição partidária em outras dimensões (Partidos de Coalização, Centrão etc.).

Convém ressaltar que as modelagens estatísticas são robustas quando se utiliza séries de dados grandes (amostras maiores que 30). Nos Estados Unidos e no Canadá, os pesquisadores encontram dados de mais de 100 anos. As séries de dados maiores e a evolução dos softwares de estatística permitiram análises para o desenvolvimento da Teoria Incremental e da Teoria do Equilíbrio Pontuado nos Estados Unidos. A Secretaria do Tesouro Nacional (STN), no Brasil, é responsável pela divulgação dos dados da consolidação das contas públicas, mas estão disponíveis em seu sítio eletrônico apenas os dados deste o ano de 2000. No caso de dados do Governo Federal são divulgados dados das receitas e despesas orçamentárias deste o ano de 1980.

Finalizando o estudo e respondendo o problema de pesquisa, os resultados demonstraram que as variáveis receita arrecadada (Hipótese 1) e o Produto Interno Bruto per capita (Hipótese 3) apresentaram efeito positivo e significativo com a execução da despesa orçamentária (variações de estabilidade e pontuadas), ou seja, maiores arrecadações e Produto Interno Bruto per capita, acarretam no incremento dos serviços públicos a nível federal. Contudo, como os recursos são escassos, deve-se observar que os níveis de gastos devem ter correlação com o crescimento da economia. A variável número de habitantes (população) tem efeito negativo e significativo com a execução orçamentária da despesa (Hipótese 2), sinalizando que o aumento do número de habitantes provoca uma diminuição no atendimento por parte do Estado em serviços públicos, principalmente com o envelhecimento da população. As variáveis da oposição partidária dos Presidentes da Câmara dos Deputados e do Senado Federal ao Presidente da República (competição política) não apresentaram significância estatística (Hipótese 4). 


\section{REFERÊNCIAS}

Abdulkabir, M., Edem, U. A., Tunde, R. S., \& Kemi, B. L. (2015). An Empirical Study of Generalized Linear Model for Count Data. J Appl Computat Math, 4: 253. DOI: $10.4172 / 2168-9679.1000253$

Abreu, W. M., Neiva, V. M., \& Lima, N. (2012). Modelos de tomada de decisão no processo orçamentário brasileiro: uma agenda de pesquisas. Revista do Serviço Público, Brasília, 63 (2): 135-155, abr/jun. DOI: https://doi.org/10.21874/rsp.v63i2.92

Adit, T. S., \& Eterovic, D. S. (2011). Political competition, electoral participation and public finance in 20th century Latin America. European Journal of Political Economy, 27, 181-200. DOI: 10.1016/j.ejpoleco.2010.06.006

Agresti, A. (2007). An Introduction to Categorical Data Analysis. Second Edition. John Wiley \& Sons, Hoboken.

Alves, M. A. (2016). O modelo incremental como teoria para o processo orçamentário. RBPO - Revista Brasileira de Planejamento e Orçamento, volume 6, n. 2, p. 124-137.

Bezdek, V., Dybczak, K., \& Krejdl, A. (2003). Fiscal Implications of Population Ageing. Finance a uvur - Czech Journal of Economics and Finance, 53, a. 11 12.

Biblioteca da Presidência da República (2019), Ex-Presidentes. Recuperado em 10 maio, 2019, de http://www.biblioteca.presidencia.gov.br/presidencia/expresidentes.

Bird, R. M. (1971). Wagner's Law of expanding state activity. Public Finance, v. 26, n. 1, p. 1-26.

Brasil (2016). Ementa Constitucional n 95/2016. Recuperado em 10 abril, 2019, de http://www.planalto.gov.br/ccivil_03/constituicao/emendas/emc/emc95.ht $\mathrm{m}$.

Brasil (1964). Lei $n^{\circ}$ 4.320/1964. Recuperado em 10 abril, 2019, de http://www.planalto.gov.br/ccivil_03/leis//4320.htm.

Brasil (2000). Lei de Responsabilidade Fiscal (Lei Complementar n 101/2000). Recuperado em 10 abril, 2019, de http://www.planalto.gov.br/ccivil_03/leis/lcp/lcp101.htm.

Breslow, N. (1996). Generalized linear models: checking assumptions and strengthening conclusions. Statistica applicate, 8: 23-41.

Cálculo Exato (2019). Atualização de um valor por um índice financeiro. Recuperado em 05 maio, 2019, de http://calculoexato.com.br/parprima.aspx?.codMenu=FinanAtualizalndice. 
Câmara dos Deputados (2019). A história da Câmara dos Deputados. Recuperado em 10 maio, 2019, de https://www2.camara.leg.br/acamara/conheca/historia/Ex_presidentesCD_ Republica.

Carvalho, D. I. (2018). Teoria do Equilíbrio Pontuado: uma análise da execução orçamentária no Brasil no período de 1980-2014. Revista do Serviço Público, 69 (1), 85-1 10, jan/mar. DOl: https://doi.org/10.21874/rsp.v69i1.1639

Chan, K. N., \& Zhao, S. (2016). Punctuated Equilibrium and the Information Disadvantage of Authoritarianism: Evidence from the People's Republic of China. The Policy Studies Journal, Vol. 44, No. 2. DOI: 10.1111/psj.12138

Cordeiro, G. M., \& Demétrio, C. G. B. (2008). Modelos Lineares Generalizados e Extensões, ESALQ, USP, Piracicaba.

Davis, O. A., Dempster, M. A. H., \& Wildavsky, A. (1966). Theory of the Budgetary Process. The American Political Science Review, v. 60, p. 529-547.

Demera, G., \& Yemer, M. (2018). Determinants of budget control in Ethiopian public organization (the case of Benishangul Gumuz regional State). Emperor International Journal of Finance and Management Research (EIJFMR), Mayas Publication, ISSN: 2395-5929, UGC Jr. No.: 45308, abr.

Fávero, L. P., (2015). Análise de dados: modelos de regressão com Excel $\AA_{\text {, Stata }}{ }$ e SPSS®. Elsevier, Rio de Janeiro.

Fávero, L. P., Belfiore, P., Silva, F. L., \& Chan, B. L. (2009). Análise de dados: modelagem multivariada para tomada de decisões. (9. Ed.). Rio de Janeiro: Elsevier.

Fernandes. A. C. C. B., \& Alves, M. A. (2017). Planejamento de políticas públicas: uma teoria na definição dos gastos federais. Negócios em Projeção, volume 8, número 1, p.139-151.

Ferris, J. S., Park, S. B., \& Winer, S. L. (2008). Studying the role of political competition in the evolution of government size over long horizons. Public Choice, 137:369401. DOI: $10.1007 /$ s1 $1127-008-9334-6$

Fittipaldi, I., Costa, S. F., \& Araújo, C. M. C. (2017). O gasto público federal brasileiro: um perfil incrementalista? Revista do Serviço Público, 68 (3) $611-630$ jul/set. DOI: https://doi.org/10.21874/rsp.v68i3.1332

Gaxie, D. (2012). As lógicas do recrutamento político. Rev. Bras. Ciênc. Polít. no.8, Brasília May/Aug. DOI: 10.1590/S0103-33522012000200007

Givel, M. (2010). The evolution of the Theoretical Foundations of Punctuated Equilibrium in public policy. Review of Policy Research, v. 17, p. 187-198. DOI: https://doi.org/10.1111/j.1541-1338.2009.00437.x 
Hegelich, S., Fraune, C., \& Knollmann, D. (2014). Point Predictions and the Punctuated Equilibrium Theory: A Data Mining Approac - U.S. Nuclear Policy as Proof of Concept. The Policy Studies Journal, Vol. 43, No. 2. DOI: $10.1111 /$ psj. 12089

Hobolt, S. B., \& Klemmensen, R. (2008). Government Responsiveness and Political Competition in Comparative Perspective. Comparative Political Studies, Volume 41 Number 3, March, 309-337. DOI: 10.1177/0010414006297169

IBGE - Instituto Brasileiro de Geografia e Estatística (2019). Produto Interno Bruto. Recuperado em 10 maio, 2019, de https://www.ibge.gov.br/explica/pib.php.

Ibrahim, M. (2016). Assessing Incrementalism in United Arab Emirates Federal Budgeting. Journal of Applied Finance \& Banking, vol. 6, no. 1, 2016, 15-28.

Jaén-García, M. (2018). Wagner's Law: A Revision and a New Empirical Estimation. Hacienda Pública Española, Review of Public Economics, 224 (1): 13-35. DOI: 10.7866/HPE-RPE.18.1.1

Jones, B., \& Baumgartner, F. R. (2012). From There to Here: Punctuated Equilibrium to the General Punctuation Thesis to a Theory of Government Information Processing. The Policy Studies Journal, Vol. 40, No. 1. DOl: https://doi.org/10.1111/j.1541-0072.2011.00431.x

Jordan, M. (2003). Punctuations and agendas: a new look at local government budget expenditures. Journal of Politics Analysis and Management, 22(3), 345360. DOI: 10.1002/pam. 10136.

Liang, K. Y. (2002). Generalized Linear Models, Estimating Functions and Multivariate Extensions. Special Invited Lecture Series in Statistical Science, (No. 2), Academia Sinica, Taipei, Taiwan.

Lindsey, J. K. (1997). Applying Generalized Linear. Springer-Verlag, New York.

Lojanica, N. (2015). Government Expenditure and Government Revenue - The Causality on the Example of the Republic of Serbia. Management International Conference - MIC. Portoroz, Slovenia, 28 e 30 maio.

Magazzino, C., Giolli, L., \& Mele, M. (2015). Wagner's Law and Peacock and Wiseman's Displacement Effect in European Union Countries: A Panel Data Study. International Journal of Economics and Financial, v. 5(3), 812-819.

Martins, G. A. \& Theóphilo, C. R. (2009). Metodologia da investigação científica para ciências sociais aplicadas. 2. ed. São Paulo: Atlas.

Matias-Pereira, J. (2012). Manual de metodologia da pesquisa Científica. 3. ed. São Paulo: Atlas.

Mehrara, M., \& Rezaei, A. A. (2014). The Relationship between Government Revenue and Government Expenditure in Iran. International Journal of 
Academic Research in Business and Social Sciences, March, Vol. 4, No. 3. DOI: 10.6007/IJARBSS/v4-i3/687

Mccullagh, P., \& Nelder, J. A., (1989). Generalized Linear Models. 2nd Edition. Chapman \& Hall, London.

Miller, T., \& Castanheira, H. C. (2013). The fiscal impact of population aging in Brazil: 2005-2050. Revista Brasileira de Estudos da População, Rio de Janeiro, v. 30, Sup., p. S5-S23. DOl: https://doi.org/10.1590/S0102-30982013000400002

Myers, R. H., Montgomery, D. C., Vining, G. G., \& Robinson, T. J., (2010). Generalized Linear Models with Applications in Engineering and the Sciences. Second Edition. John Wiley \& Sons, Hoboken.

Ollaik, L. G., Wenceslau, J., Serpra, S. M. H. C., \& Medeiros, J. J. (2011). Novas direções para pesquisas orçamentárias no Brasil. Revista de Políticas Públicas., São Luís, v.15, n.2, p. 347-357, jul./dez.

Olsson, U. (2002). Generalized Linear Models: An Applied Approach. Studentlitteratur, Lund.

Padgett, J. F. (1980). Bounded Rationality in Budgetary Research. The American Political Science Review, Vol. 74, No. 2 (Jun.), pp. 354-372.

https://www.jstor.org/stable/1960632.

Rosenthal, M., \& Wolfson, A. (2013). The Determinants of Government Budgetary Implementation: Policy Analysis of the Israeli Case. Journal of Comparative Policy Analysis: Research and Practice, Volume 15, 19 nov. Issue 5, Pages 432451. DOI: 10.1080/13876988.2013.848050

Rosoiv, I. (2015). The impact of the government revenues and expenditures on the economic growth. Procedia Economics and Finance, v. 32, 526 - 533. DOI: http://doi.org/10.4038/kjm.v8i1.7559

Sabatier, P. (2007). The need for better theories. In P. Sabatier (Ed.). Theories of the policy process (2nd ed., pp. 3-17). Colorado: Westview Press.

Sakurai, S. N. (2009). Ciclos políticos nas funções orçamentárias dos Municípios Brasileiros: uma análise para o período 1990 - 2005 via dados em painel. Estudos Econômicos., São Paulo, 39(1): 39-58, jan-mar. DOl: http://dx.doi.org/10.1590/S0101-41612009000100002

Senado Federal (2019). Senadores. Recuperado em 14 maio, 2019, de https://www25.senado.leg.br/web/senadores/presidentes.

Silva, A. M. (2017). Os ciclos do presidencialismo de coalizão e seus determinantes político-econômicos. Revista Brasileira de Ciência Política, no 24. Brasília, setembro - dezembro, pp 49-80. DOl: http://dx.doi.org/10.1590/0103335220172401 . 
Silva, S. S., \& Triches, D. (2014). Uma Nota Sobre Efeitos de Gastos Públicos Federais Sobre o Crescimento da Economia Brasileira. Revista Brasileira de Economia, Rio de Janeiro, v. 68 n. 4, p. 547-559, Out-Dez. DOl: http://dx.doi.org/10.1590/S0034-71402014000400006

STN - Secretaria do Tesouro Nacional (2019), Séries históricas. Recuperado em 04 abril, 2019, de https://www.tesouro.fazenda.gov.br/pt/-/serieshistoricas?redirect=https\%3A\%2F\%2Fwww.tesouro.fazenda.gov.br\%2Fpt\%2Fm odelo-artigo-contabilidade-

publica\%3Fp_p_id\%3D3\%26p_p_lifecycle\%3D0\%26p_p_state\%3Dmaximized\%2 6p_p_mode\%3Dview\%26_3_keywords\%3Ds\%25C3\%25A9ries\%2Bhist\%25C3\%25 B3ricas\%26_3_struts_action\%3D\%252Fsearch\%252Fsearch\%26_3_redirect\%3D\% 252Fpt\%252Fsobre-contabilidade-publica\%26_3_y\%3D0\%26_3_x\%3D0.

Swan, T. (2006). Generalized estimating equations when the response variable has a Tweedie distribution: An application for multi-site rainfall modelling. Department of Mathematics and Computing the University of Southern Queensland, Toowoomba, QLD, July 7.

Tarouco, G. S., \& Dantas Neto, P. F. (2017). Elites, partidos e competição política: Brasil e Argentina. Caderno CRH, Salvador, v. 30, n. 80, p. 213-216, Maio/Ago. DOI: 10.1590/s0103-49792017000200001

Thomson, R., Royed, T., Naurin, E., Artés, J., Costello, R., Ennser-Jedenastik, L., Ferguson, M., Kostadinova, P., Moury, C., Pétry, F., \& Praprotnik, K. (2017). The Fulfillment of Parties' Election Pledges: A Comparative Study on the Impact of Power Sharing. American Journal of Political Science, Vol. 61, No. 3, July, Pp. 527-542. DOI: 10.1111 /ajps.12313

True, J., Jones, B. \& Baumgartner, F. (2007). Punctuated equilibrium theory: explaining stability and change in public policymaking. In P. Sabatier (Eds.). Theories of the policy process (2nd ed., pp. 155-187). Westview Press, Colorado.

Ukwueze, E. R. (2015). Determinants of the Size of Public Expenditure in Nigeria. SAGE Open, 28, 1-8, October-December. DOI: 10.1177/2158244015621346.

Wong, L. L. R., \& Carvalho, J. A. (2006). O rápido processo de envelhecimento populacional do Brasil: sérios desafios para as políticas públicas. Revista Brasileira de Estudos da População, São Paulo, v. 23, n. 1, p. 5-26, jan./jun. 2006. DOl: http://dx.doi.org/10.1590/S0102-30982006000100002

Zaed, A. B. (2017). Increasing Public Expenditure. International Journal of Scientific \& Technology Research, Volume 6, Issue 04, April.

Zokalj, M. (2016). The impact of population aging on public finance in the European Union. Financial Theory and Practice, 40 (4) 383-412. DOI: 10.3326/fintp.40.4.2 


\section{CONTRIBUIÇÕES DOS AUTORES}

\begin{tabular}{|l|c|c|c|}
\hline \multicolumn{1}{|c|}{ Contribuição } & $\begin{array}{c}\text { Maurício } \\
\text { Corrêa da } \\
\text { Silva }\end{array}$ & $\begin{array}{c}\text { João Carlos } \\
\text { Hipólito } \\
\text { Bernardes do } \\
\text { Nascimento }\end{array}$ & $\begin{array}{c}\text { José Dionísio } \\
\text { Gomes da Silva }\end{array}$ \\
\hline $\begin{array}{l}\text { 1. Idealização e concepção do assunto } \\
\text { e tema da pesquisa }\end{array}$ & $\checkmark$ & $\checkmark$ & \\
\hline 2. Definição do problema de pesquisa & $\checkmark$ & $\checkmark$ & \\
\hline $\begin{array}{l}\text { 3. Desenvolvimento da Plataforma } \\
\text { Teórica }\end{array}$ & $\checkmark$ & $\checkmark$ & \\
\hline $\begin{array}{l}\text { 4. Delineamento da abordagem } \\
\text { metodológica da pesquisa }\end{array}$ & $\checkmark$ & $\checkmark$ & \\
\hline 5. Coleta de dados & $\checkmark$ & $\checkmark$ & \\
\hline $\begin{array}{l}\text { 6. Análises e interpretações dos dados } \\
\text { coletados }\end{array}$ & $\checkmark$ & $\checkmark$ & \\
\hline 7. Conclusões da pesquisa & $\checkmark$ & & \\
\hline 8. Revisão crítica do manuscrito & $\checkmark$ & & \\
\hline $\begin{array}{l}\text { 9. Redação final do manuscrito, } \\
\text { conforme as normas estabelecidas pela } \\
\text { Revista. }\end{array}$ & & & $\checkmark$ \\
\hline 10. Orientação & & & \\
\hline
\end{tabular}

